\title{
21. Yüzyıl Becerileri Öğretimi Ölçeğinin Türk Kültürüne Uyarlanması: Geçerlik Güvenirlik Çalışması
}

DOI: $10.26466 /$ opus.725042

*

\section{Melike Özyurt*}

*Dr Öğretim Üyesi,Gaziantep Üniversitesi, Gaziantep Eğitim Fakültesi, Gaziantep/ Türkiye E-Posta: melike.ozyurt@yahoo.com

ORCID: $\underline{0000-0003-4527-9343}$

Öz

Bu araştırmanın amacl, 21. Yüzyıl Becerileri Öğretimi Ölçeğini Türk kültürüne uyarlamaktır. Araştırma 2019-2020 Akademik Yılı Güz Dönemi'nde 233 öğretmen adayı ile yürütülmüştür. Ölçek öğretmen adaylarının 21.yüzyıl becerilerinin öğretimine ilişkin özyeterlik algılarının ölçülebilmesi amacına hizmet etmekte olup, 10 madde ve üç faktörden oluşmaktadır. Ölçeğin alt faktörleri; teknolojinin faydası, işbirliği ile yenilik ve problem çözmedir. Ölçeğin Türkçe'ye uyarlama sürecinde dil geçerliği, kavramsal ve deneyimsel eşdeğerlik, yapı geçerliği, ölçüt geçerliği ile güvenirlik çalışmaları gerçekleştirilmiştir. Ölçeğin Türkçe formunun dilsel geçerliğini sağlamak için çeviri geri çeviri tekniği uygulanmış ve uzman görüşlerine başvurulmuştur. Yapı geçerliğini test etmek için Doğrulayıcı Faktör Analizi (DFA) uygulanmıştır. Ölçüt geçerliğini sınamak için ölçeğin tamamı ile her bir alt-faktör arasındaki korelasyon incelenmiştir. Güvenirlik çalışmaları kapsamında ise ölçeğin Cronbach Alfa (iç tutarlık) güvenirlik katsayıları, testi yarılama güvenirliği, madde toplam korelasyonları ve madde ayırt edicilik değerleri hesaplanmıştır. Araştırma sonucunda, 21. Yüzyıl Becerileri Öğretimi Ölçeği Türkçe Formu' nun öğretmen adaylarının 21. yüzyıl becerileri öğretimine ilişkin özyeterlik algılarını ölçmek amacryla kullanılabilecek geçerli ve güvenilir bir ölçme aracı olduğu belirlenmiştir.

Anahtar Kelimeler: 21. yüzyıl becerileri öğretimi, ölçek uyarlama, güvenirlik ve geçerlik, öğretmen adayları. 


\title{
Adaptation of 21st Century Skills Teaching Scale to Turkish Culture: A Validity-Reliability Study
}

\begin{abstract}
The purpose of the study was to adapt the 21st Century Skills Teaching Scale into Turkish Culture. The research was conducted with 233 prospective teachers in the Fall Term of 2019-2020 Academic Year. The scale serves the purpose of measuring prospective teachers' self-efficacy perceptions regarding the teaching of $21^{\text {st }}$ century skills and consists of 10 items and three factors. Sub-factors of the scale are utility of technology, collaboration and innovation \& problem solving. In the adaptation process of the scale to Turkish, linguistic validity, conceptual and experiential equivalence, construct validity, criterion validity and reliability studies were carried out. In order to ensure the linguistic validity of the Turkish form of the scale, translation back translation technique was applied and expert opinions were asked. Confirmatory Factor Analysis (CFA) was applied to test the construct validity. To test the criterion validity, the correlation between the whole scale and each sub-factor was examined. Within the scope of reliability studies, Cronbach Alfa (internal consistency) reliability coefficients of the scale, halftest reliability, item total correlations and item discrimination values were calculated. As a result of the research, it has been determined that the $21^{\text {st }}$ Century Skills Teaching Scale Turkish Form is a valid and reliable measurement tool that can be used to measure the self-efficacy perceptions of prospective teachers regarding $21^{\text {st }}$ century skills teaching.
\end{abstract}

Keywords: $21^{\text {st }}$ century skills teaching, scale adaptation, validity and reliability, pre-service teachers. 


\section{Giriş}

Teknolojik gelişmeler, bilimsel yenilikler, küreselleşme, değişen işgücü talepleri, ekonomik baskılar ve günümüz toplumunda hızla değişen rekabet anlayışı, bireylerin topluma katkıda bulunmaları ve hayata hazır olmalarını sağlamak için kazanılması gereken becerilerin yeniden tanımlanmasına neden olmuştur (Levy ve Murnane, 2005; Stewart, 2010 ve Wilmarth, 2010). 21. yüzyıl becerileri olarak tanımlanan bu beceriler, içinde bulunduğumuz yüzyılın gerekleri çerçevesinde eğitim, iş, sosyal yaşam gibi hayatın birçok alanında bireylerin ihtiyaç duydukları becerileri kapsamaktadır. Başka bir ifade ile 21. yüzyıl becerileri yaşadığımız yüzyılda ihtiyaç duyulan ve eğitimi verilen beceriler olarak da tanımlanabilir (Griffin, McGaw ve Care, 2012).

21. yüzyıl becerilerinin belirlenmesi ve sinflandırılması konusunda birçok kurum ve kuruluş çalışmalar yapmıştır. Alanyazında bu konudaki çalışmaları ile öne çıkan bazı kurum ve kuruluşlar; 21. Yüzyıl Becerileri Ortaklığı (P21, Partnershipfor 21 ${ }^{\text {st }}$ Century Learning), 21. Yüzyıl Becerilerinin Öğretimi ve Değerlendirilmesi (ATCS, Assessment and Teaching of $21^{\text {st }}$ Century Skills), Ekonomik Kalkınma ve İşbirliği Örgütü (OECD, Organization for Economic Co-operation and Development), Asya-Pasifik Ekonomik İşbirliği Forumu (APEC, Asia-Pacific Economic Cooperation), Uluslararası Eğitimde Teknoloji Topluluğu (ISTE, International Society forTechnology in Education), Kuzey Merkez Bölge Eğitim Laboratuvarı (NCREL, North Central Regional Educational Laboratory), Avrupa Komisyonu (EC, European Comission) olarak sıralanabilir. Bu konuda yaptığı çalışmalarla alanyazında en çok kabul gören P21, 21. yüzyıl becerilerini üç kategoride ele almaktadır. Buna göre;

1. Öğrenme ve Yenilenme Becerileri Kategorisi: Eleştirel düşünme ve problem çözme, yaratıcı düşünme ve yenilikçilik, iletişim, işbirliği becerilerini,

2. Yaşam ve Kariyer Becerileri Kategorisi: Esneklik ve uyum, girişimcilik ve özyönetim, sosyal ve kültürlerarası beceriler, üretkenlik ve sorumluluk, liderlik ve sorumluluk becerilerini,

3. Bilgi, Medya ve Teknoloji Kategorisi: Bilgi okuryazarlığı, medya okuryazarlığı ve bilgi iletişim teknolojileri okuryazarlığı becerilerini kapsamaktadır (P21, 2009b). 
ATCS ise 21.yüzyıl becerilerini dört kategoride sınıflamıştır. Bu sınıflamaya göre;

1. Düşünme Yollan Kategorisi: Yaratıı düşünme ve yenilikçilik, eleştirel düşünme, problem çözme ve karar verme ile öğrenmeyi öğrenme becerilerini,

2. Çalışma Yollan Kategorisi: İletişim, işbirliği ve ekip çalışması becerilerini,

3. Çalışma Araçlan Kategorisi: Bilgi okuryazarlığı ve bilgi iletişim teknolojileri okuryazarlığı becerilerini,

4. Dünyada Yaşama Kategorisi: Vatandaşlık, yaşam ve kariyer becerileri ile bireysel ve toplumsal sorumluluk becerilerini içermektedir (Binkley, Erstad, Herman, Raizen, Ripley ve Rumble, 2010; Griffin, McGaw ve Care, 2012).

OECD'ye (2005) göre ise 21. yüzyıl becerileri; teknolojik araçların kullanımı, heterojen gruplarla etkileşim ve bağımsız davranışlar sergileyebilme olarak sınıflandırılmaktadır. APEC (2008), 21. yüzyıl becerilerini yaşamboyu öğrenme, problem çözme, öz yönetim ve işbirlikli takım çalışması olarak; NCREL (2003) ise bu becerileri; yaratıcı düşünme, etkili iletişim, yüksek üretkenlik ve dijital çağ okuryazarlığı olarak tanımlamaktadır. Bir başka sınıflama yapan NETS/ISTE'ye (2007) göre de bu beceriler; yaratıcılık ve yenilenme (eleştirel düşünme, problem çözme ve karar verme), iletişim ve işbirliği, dijital vatandaşlık, teknolojik uygulamalar ve kavramlar, araştırma ve bilgi akıcılığı şeklinde belirlenmiştir. EC (2018) ise 21. yüzyıl becerilerine ilişkin sekiz anahtar yetkinlik belirlemiştir. Bu yetkinlikler; 1- Çeşitli alanlardaki okuryazarlık yetkinliği, 2- Çok dillilikte yetkinlik, 3- Matematik, fen, teknoloji ve mühendislik alanlarında yetkinlik, 4- Dijital yetkinlik, 5- Kişisel, sosyal ve öğrenmeyi öğrenme yetkinliği, 6- Vatandaşlık konusunda yetkinlik, 7- Girişimcilik alanında yetkinlik ve 8- Kültürel farkındalık ve ifadede yetkinlik olarak tanımlanmıştır. Her ne kadar oluşturulan sınıflamalar/çerçeveler farklılık gösterse de, tüm bu sınıflamalarda bazı becerilerin ortak şekilde yer aldığı ve öne çıktı̆̆ görülmektedir. Buradan yola çıkarak; 21. yüzyılda bireylerden özellikle, teknoloji kullanımı, işbirlikli çalışma, etkili iletişim, dijital okuryazarlık, problem çözme, eleştirel düşünme, yaratıcllı ve üretkenlik ile farklı kaynaklardan bilgi edinme gibi becerilerde yetkin olmalarının beklendiği 
söylenebilir (Gore, 2013; Voogt ve Roblin, 2012). Bununla birlikte yeni okuryazarlık biçimleri ile sosyal, kültürel ve bilişsel farkındalık da önemli 21. yüzyıl becerileri arasında yer almaktadır (EC, 2018; Griffin ve Care, 2014). Bu sınıflamalarda öne çıkan beceriler incelendiğinde 21. yüzyıl becerilerinin hem bilgiyi ve hem de uygulamayı içeren kompleks beceriler olduğu görülmektedir. 21. yüzyıl becerileri özetle; bilgiyi edinmeyi, anlamayı ve uygulamayı içermekte, bilgi ve becerilerin sentezinden oluşmaktadır (Dede, 2010).

Yaşadığımız yüzyılda bireylere 21. yüzyıl becerilerinin kazandırılması, artık bireyler için temel bir hakka dönüşmüştür (Autor, Levy ve Murnane, 2003; P21, 2008). Çünkü 21. yüzyıl becerilerine sahip olmak, bireyleri hem iş yaşamlarında, hem de eğitim hayatlarında başarılı kılmaktadır (Ball, Joyce ve Anderson-Butcher, 2016). Bunların yanısıra Louis' e (2012) göre bireylerin eğitim hayatındaki başarıları için bu becerileri çok erken yaşta kazanmaları gerekmektedir. Uluslararası rekabette ve işgücünde var olabilmek için de bireylere bu becerilerin kazandırılmasının gereklilik olduğu görüşü (Saavedra ve Opfer, 2012); eğitim, politika ve iş alanından birçok uzman tarafından desteklenmektedir (Chiarle, 2017; NRC, 2012a; Rotherdam ve Willingham, 2009 ve Walser, 2008). Bu becerilerin kazanımınin zorunlu hale gelmesinin temel nedeni olarak, teknolojide devrim niteliğinde gerçekleşen değişim gösterilebilir. Çünkü bu değişim toplumun kültürel yaşantısına büyük etkide bulunmakla birlikte, küresel pazardaki rekabetten dolayı bireylerin iş ortamında 21. yüzyıl becerilerine duyacakları ihtiyacı da arttırmaktadır (Kellner, 2000 ve P21, 2019). Ayrıca, bireylerin 21.yüzyıl becerilerine sahip olmaları; bilgiyi doğru okuyup anlamlandırmaları, sürekli kendilerini geliştirerek çağa ayak uydurmaları, ortaya çıkan farklı sorunlar veya gelişmeler karşısında doğru adımı atabilmeleri için de önemlidir (Walser, 2008).

21. yüzyıl becerilerinin bireylere kazandırılması eğitim ile gerçekleşebilir. Bunun için son yıllarda birçok ülke eğitim programlarında; eleştirel düşünme, problem çözme, karar verme, iletişim, işbirliği ve vatandaşlık gibi 21. yüzyıl becerilerini kazandırmaya yönelik güncellemeler yapmıştır. Bazı ülkeler de eğitim programlarına, bilgi okuryazarlığı ve bilgi iletişim teknolojileri okuryazarlığı becerilerini eklemişlerdir (Adamson ve Darling-Hammond, 2015). Özellikle $A B D^{\prime}$ de bu çalışmalar geniş bir perspektifte ele alınmıştır (Gelen, 2017). Bununla birlikte Hong Kong, Japonya, Çin, Finlandiya ve Singapur' da da bu konuda önemli adımlar atıldığı, bazı eğitim reformlarının 
hayata geçirildiği görülmektedir. Bu konuda Hong Kong'ta öğrenmeyi öğrenme temalı eğitim reformu, Japonya'da çözüm yolunu ezberleme yerine problemi tanımlama ve çözmeye, deneyimlemenin önemine odaklanan eğitim reformu hayata geçirilmiştir. Çin eğitim sisteminde ise öğrencilerin; iletişim, takım çalışması, problem oluşturma ve çözme ile öğrenmeyi öğrenme becerilerinin geliştirilmesine daha çok önem verilmiştir (OECD, 2010). Finlandiya eğitim sisteminde ise vatandaşlık becerilerinin geliştirilmesine odaklanılmış, programlarda bireylerin; yaratıcı düşünme ve problem çözme gibi düşünme becerilerinin, çalışma ve etkileşim şekillerine yönelik becerilerinin, el becerileri - kendini ifade etme becerilerinin, katılım-inisiyatif alma becerilerinin ve bireysel farkındalık-sorumluluk becerilerinin geliştirilmesi hedeflenmiştir (OntarioMinistry of Education,2010). Singapur' da da 21. Yüzyıl Becerileri ve Öğrenci Çıktıları Çerçevesi oluşturularak, öğrencilerin küresel fırsatlardan daha çok fayda sağlayabilmesi için eğitilmeleri konusunda çalışmalar yapılmıştır (Singapore Ministry of Education, 2010).

Türkiye'de ise bu konudaki ilk girişim, geleceğin mesleki gereksinimlerini belirlenmesi ilişkin çalışma ile Türkiye İş Adamları Derneği (TÜSİAD) tarafından gerçekleştirilmiştir. Yapılan çalışmada 21. yüzyıl becerilerinin öğrencilere kazandırılması için Türk eğitim sisteminde atılabilecek adımlar konusunda öneriler getirilmiştir (TÜSİAD, 2012). Milli Eğitim Bakanlığı (MEB) da bu konuda önemli çalışmalar gerçekleştirmiştir. MEB tarafından, Avrupa Parlamentosu'nun 2008 yılında onayladığ "Avrupa Yeterlilikler Çerçevesi" doğrultusunda "Milli Eğitim Kalite Çerçevesi" ve "Türkiye Yeterlilikler Çerçevesi" oluşturulmuştur. Bu çerçeveler bağlamında ana dilde iletişim, yabanc dillerde iletişim, matematiksel yetkinlik ve bilim/teknolojide temel yetkinlikler, dijital yetkinlik, öğrenmeyi öğrenme, sosyal ve vatandaşlıkla ilgili yetkinlikler, inisiyatif alma ve girişimcilik ile kültürel farklılık ve ifade olmak üzere sekiz anahtar yetkinlik belirlenmiştir. Bu yetkinliklere tüm öğretim programlarında yer verilerek, 21. yüzyıl becerilerinin öğretim programlarına entegrasyonu sağlanmıştır (TTKB, 2017).

Türkiye'de her ne kadar 21.yüzyıl becerileri, öğretim programlarına dâhil edilerek, bireylere bu becerilerin kazandırılmasına yönelik etkili bir adım atılmış olsa da, eğitim-öğretim sürecinin en önemli bileşenlerinden bir olan öğretmenlerin, bu konuda yeterliği sağlanmadan bu becerilerin öğrencilere kazandırılmasının beklenemeyeceği açıktır. Çünkü bu becerilerin kazanımında öğretmenlerin öğrencilere yapacağı rehberlik son derece önemlidir (Walser, 
2008). Bununla birlikte öğretmenler öğrenme ortamlarının oluşturulmasında ve etkinliklerin düzenlenmesinde de önemli role sahiptir (Griffin, McGaw ve Care, 2012). Bu konuda başarıya ulaşılabilmesi için, öğretmenlerin okul ve okul dışında düzenledikleri etkinlikler, uyguladıkları strateji ve yöntemlerle öğrencilerin bu becerileri kazanmasına olanak sağlamaları (Cansoy, 2018), bu becerileri öğrenme-öğretme sürecinde kendilerinin de kullanmaları gerekmektedir. Bu durum öğretmenlerin de bu becerilere sahip olmasını gerekli kılmaktadır (Anagün, Atalay, Kılıç ve Yaşar, 2016; Gürültü, Aslan ve Alcı, 2019).

Saavedra ve Opfer'a (2012) göre, öğrencilere 21. yüzyll becerilerini kazandırabilmek için öğretmenlerin de bu becerileri geliştirebilecek düzeyde yetiştirilmeleri gerekmektedir. Benzer şekilde P21 (2008) ve Rotherdam ve Willingham (2009) de bu konuda hedefe ulaşlabilmesi için, öğretmen eğitiminin önemine vurgu yapmışlardır. Tüm bu araştırma sonuçları, öğretmen yetiştiren kurumların, öğrencilerin 21. yüzyıl becerilerini geliştirebilecek nitelikte öğretmen yetiştirme konusundaki sorumluluklarını arttırmaktadır. Bu durum aynı zamanda, öğretmen adaylarının 21.yüzyıl becerilerinin öğretimine ilişkin yeterliklerinin belirlenmesini de gerekli kılmaktadır.

İlgili alanyazın incelendiğinde; ilkokul öğrencilerinin (Belet-Boyacı ve Atalay, 2016), ortaokul öğrencilerinin (Ball, Joyce ve Anderson-Butcher, 2016; Kang, Kim, Kim ve You, 2012; Karakaş, 2015; Ongardwanich, Kanjanawasee ve Tuipae, 2015), ortaokul ve lise öğrencilerinin (Kang, Heo, Jo, Shin ve Seo, 2010), lise öğrencilerinin (Arsad, Osman ve Soh, 2011; Osman, Soh ve Arsad, 2010), lise ve üniversite öğrencilerinin (Çevik ve Şentürk, 2019), üniversite öğrencilerinin (Yılmaz ve Alkış, 2019), öğretmen adaylarının (Anagün, Atalay, Kılıç ve Yaşar, 2016; Tondeur, Aesaert, Pynoo, vanBraak, Fraeyman ve Erstad, 2017), öğretmenlerin (Keskin ve Yazar, 2015) 21. yüzyıl becerilerinin belirlenmesine yönelik ölçek geliştirme/uyarlama çalışmalarının yapıldığı görülmektedir. Bununla birlikte alanyazında; öğretmenlerin 21. yüzyıl becerilerini kullanım durumlarını (Deborah, 2012), öğretmen adaylarının 21. yüzyıl öğreten becerilerini ve öğrenen becerilerini kullanım durumlarını (Orhan Göksun, 2016) belirlemeye ilişkin ölçme araçları da yer almaktadır. Bu çalı̧̧malardan farklı olarak Jia, Oh, Sibuma, LaBanca ve Lorentson (2016) ise öğretmen adaylarının ve öğretmenlerin 21. yüzyıl becerilerinin öğretimine ilişkin özyeterlik algılarını ölçmeye yönelik ölçek geliştirme çalışması gerçekleştirmişlerdir. 
Sunulan bilgilerde görüldüğü üzere alanyazında öğrencilerin, öğretmenlerin ve öğretmen adaylarının 21. yüzyıl becerilerini ölçmeye veya bu becerileri kullanım durumlarını belirlemeye yönelik birçok ölçek geliştirme çalışması yer almaktadır. Ancak öğretmen adaylarının 21. yüzyıl becerilerinin öğretimine ilişkin yeterliklerini belirlemeye yönelik Türkiye'de geliştirilmiş veya Türkçe'ye uyarlanmış bir ölçme aracına erişilememiştir. Öğretmenlerin, 21. yüzyıl becerilerinin edinimindeki rolü göz önünde bulundurulduğunda, göreve yeni başlayacak öğretmen adaylarının bu yeterliğe sahip olma düzeylerinin belirlenmesine yönelik bir ölçme aracının Türkçe'ye uyarlama çalışmasının yapılması ihtiyaç olarak görülmüştür. Bu çerçevede araştırmanın amacl; öğretmen adaylarının 21. yüzyıl becerilerinin öğretimine ilişkin yeterliklerini ortaya koyabilecek geçerli ve güvenilir bir ölçme aracı olan "21. Yüzyıl Becerileri Öğretimi Ölçeği”ni Türkçe'ye uyarlamak ve ölçeğin psikometrik özelliklerini incelemektir.

Araştırma, alanyazındaki bu boşluğun doldurması ve henüz eğitimine devam eden öğretmen adaylarının 21. yüzyıl becerilerinin öğretimine ilişkin yeterliklerinin belirlenmesine olanak sağlaması yönüyle gerekli görülmektedir. Araştırma ayrıca eğitimcilere, program geliştirmecilere ve araştırmac1lara, Türkiye'deki mevcut uygulamalar ve öğretmen yetiştirme programı ile öğretmen adaylarına 21. yüzyıl becerinin öğretimine ilişkin yetkinliklerin ne ölçüde kazandırıldığının tespitine olanak sağlaması ve öğretmen yetiştirme programlarının ve uygulamaların bu bağlamda etkililiğine ilişkin veri sunabilecek olmasından dolayı da önemli görülmektedir.

\section{Yöntem}

\section{Çalışma Grubu}

Araştırmanın çalışma grubu 2019-2020 akademik yılı güz döneminde, Gaziantep Üniversitesi Eğitim Fakültesi sınıf öğretmenliği, matematik öğretmenliği ve Türkçe öğretmenliği programlarının, üçüncü ve dördüncü sınıflarında öğrenim görmekte olan 233 öğretmen adayından oluşmaktadır. Katılımcıların 176'ü kadın, 57'si erkektir. Katılımcı sayısı belirtilirken, ölçeği eksik doldurulan 21 öğretmen adayı çalışma grubu dışında tutulmuştur. Tablo 1'de çalışma grubunda yer alan katılımcıların programlara göre dağılımı sunulmaktadır. 
Tablo 1. Katılımcılarn programlara göre dă̆ılımı

\begin{tabular}{lll}
\hline Program & f & \% \\
\hline Matematik Öğretmenliği & 102 & 44,1 \\
Sinuf Öğretmenliği & 73 & 31,2 \\
Türkçe Öğretmenliği & 58 & 24,7 \\
Toplam & 233 & 100,0 \\
\hline
\end{tabular}

Alanyazında faktör analizi çalışmalarında örneklem büyüklüğü için çeşitli görüşler yer almaktadır. Comrey ve Lee' ye (1992) göre faktör analizinde 200 katılımcıdan oluşan örneklem büyüklügünü yeterli düzeydedir. Floyd ve Wideman (1995) ile Bryman ve Cramer' e (2001) göre ise açımlayıcı ve doğrulayıcı faktör analizleri için ölçekte yer alan madde sayısının on katı kadar katılımcının çalışma grubunda yer alması gerekmektedir. Kline (2011) de doğrulayıcı faktör analizi sürecinde madde sayısının 10 katı kadar katılımcıdan veri toplamanın yeterli olacağını ifade etmektedir. Ölçekte yer alan madde sayısı 10'dur. Buna göre katılımcı sayısının faktör analizi çalışması için yeterli olduğu söylenebilir.

\section{Yüzyıl Becerileri Öğretimi Ölçeği}

“21. Yüzyıl Becerileri Öğretimi Ölçeği” Jia, Oh, Sibuma, LaBanca ve Lorentson (2016) tarafından geliştirilmiştir. Ölçek öğretmen adaylarının 21.yüzyıl becerilerinin öğretimine ilişkin öz yeterlik algılarının ölçülebilmesi amacı ile geliştirilmiştir. Ölçek geliştirme süreci incelendiğinde, ölçeğin ilk halinin 16 maddeden oluştuğu ancak, Açımlayıc Faktör Analizi (AFA) ve Doğrulayıcı Faktör Analizi (DFA) çalışmaları sonucunda ölçeğin 10 madde ve üç faktörlü bir yapı kazandığı görülmüştür. Ölçeğin alt faktörleri teknolojinin yararı (3 madde), işbirliği (3 madde), yenilik ve problem çözme (4 madde) olarak adlandırılmıştır. Ölçeğin alt faktörlerine ilişkin Cronbach Alfa değerleri ise sırasıyla teknolojinin yararı .81 , işbirliği .75 , yenilik ve problem çözme .83 olarak hesaplanmıştır. Üç faktörlü bu yapı varyansın \% 68'ini açıklamaktadır. Ölçek 7'li likert tipindedir ve derecelendirmesi tamamen yeterliyim (7), hiç yeterli değilim (1) olarak belirlenmiştir. Ölçekten alınabilecek en yüksek puan 70, en düşük puan ise 7'dir. Ölçekte ters (olumsuz) madde bulunmamaktadır. Ölçekten alınan puanın yüksek olması öğretmen adayının 21. yüzyıl becerilerinin öğretimine ilişkin öz yeterlik algısının yüksek olduğunu göstermektedir. 


\section{Ölçeğin Türkçe' ye Uyarlanması Süreci}

Uyarlama çalışması sürecinde ilk olarak Dr Yueming Jia ile e-posta yoluyla iletişime geçilerek ölçeğin Türkçe'ye uyarlama çalışması için izin alınmıştır. Sonrasında ölçek, amaca hizmet etme yeterliliği açısından incelenmek üzere 21.yüzyıl becerileri konusunda çalışma yapan üç öğretim üyesinin görüşüne sunulmuş ve yeterli bulunmuştur. Bunun yanı sıra ölçeğin dil geçerliği, yapı geçerliği ve ölçüt geçerliğini sağlamak için de çalışmalar yapılmış, ölçeğin Türkçe formunun güvenirliği test edilmiştir.

Orijinali İngilizce olan ölçeğin dil geçerliğini sağlamak için çeviri geri çeviri tekniği uygulanmıştır (Sperber, 2004; Looman ve Farrag, 2009). Bu aşamada ölçek ilk olarak Eğitim Bilimleri doktoralı bir dil bilimci tarafından Türkçe'ye çevrilmiştir. Sonrasında bu çeviri Eğitim Bilimleri doktoralı başka bir dil bilimci tarafından İngilizce'ye çevrilmiştir. Bu çeviriler yapılırken her iki dilin (Türkçe ve İngilizce) kültürel, psikolojik ve gramer farklılıklarının dikkate alınmasına özen gösterilmiştir (ITC, 2018). Çeviri işlemleri tamamlandıktan sonra araştırmacı, çeviriyi yapan dil bilimciler ve 21.yüzyıl becerileri konusunda uzman iki akademisyen bir araya gelerek çeviriler arasındaki uyumu incelemişlerdir. Ayrıca kelimenin veya sözcük grubunun birebir çevirisinden ziyade kavramsal eşdeğerliğinin sağlanabilmesi, çevirinin dil açısından basit, açık ve özlü olması (Çapık, Gözüm ve Aksayan, 2018) amacı ile İngilizce ifadeleri en iyi karşılayan Türkçe terminolojiyi ve ifadeleri belirlemeye yönelik çalışma yapılarak ölçeğin Türkçe formu oluşturulmuştur. Sonrasında oluşturulan bu form anlaşılırlık açısından değerlendirilmek üzere iki Türk dili uzmanın görüşüne sunulmuştur. Bu kapsamda ölçek maddelerinin anlaşılırlığı, ifadelerin akıcılığı incelenmiş, ölçek maddelerini daha anlaşılır hale getirecek düzenlemeler yapılmıştır. Örneğin" Öğrencilere bir grup projesinde liderlik etmeyi öğretmekte" olarak Türkçeye çevrilen ifade "Öğrencilere bir grup projesine liderlik yapmayı öğretmekte" şeklinde düzenlenmiştir. Bu aşamadan sonra ölçeğin, anlamsal, kavramsal, dilsel ve deneyimsel eşdeğerliğini test etmek amacı ile Türkçe ve İngilizce formlar her iki dilde de yetkin olmaları sebebi ile İngilizce öğretmenliği programı dördüncü sınıfta öğrenim görmekte olan 42 öğretmen adayına aralıklı olarak uygulanmıştır. Önce Türkçe formun sekiz hafta sonra da İngilizce formun uygulanması ile elde edilen toplam puanların arasındaki ilişki .853 olarak hesaplanmıştır. Bu çerçevede orijinal form ile eşdeğerliği sağlanmış olan Türkçe formun pilot uygulaması 
sınıf öğretmenliği(6), matematik öğretmenliği(7) ve Türkçe öğretmenliği(5) programlarında öğrenim görmekte olan 18 öğretmen adayı ile gerçekleştirilmiş. Pilot uygulama sonrası alınan geri bildirimler çerçevesinde, ölçeğin derecelendirmesinde değişiklik yapılarak; sadece 7' den 1' e rakamların belirtildiği derecelendirmeye Tamamen Yeterliyim(7), Hiç Yeterli Değilim(1) ifadeleri eklenmiş ve derecelendirmenin daha açı ve anlaşılır olması sağlanmıştır. Bu son düzenleme ile ölçek uygulamaya hazır hale getirilmiştir.

Ölçeğin yapı geçerliliğini incelemek için yapılacak analiz adımlarını belirlemek üzere, ölçek geliştirme konusunda uzman iki ve 21. yüzyıl becerileri alanında çalışmalar yürüten üç öğretim üyesi ile görüşülmüştür. Bu görüşmeler neticesinde 21.yüzyıl becerilerinin evrensel bir anlayışı temsil etmesinden dolayı ölçeğin maddelerinde kültürler arası bir fark olmadığına kanaat getirilmiş ve ölçeğin yakın zamanda geliştirilmiş olması da göz önünde bulundurularak, ölçeğin yapı geçerliği çalışmalarında DFA uygulanmasının yeterli olacağına karar verilmiştir (Güngör , 2016). Ölçeğin ölçüt geçerliği çalışmaları kapsamında, ölçeğin tamamı ile her bir faktör arasındaki ilişkinin incelenmesi yoluna gidilmiştir. Ölçeğin güvenilirliği için ise, ölçeğin tamamının ve alt boyutlarının iç tutarlılık katsayılarına, madde-toplam korelasyonlarına ve madde ayırt edicilikleri test edilmiştir. Ölçüt geçerliği ve güvenirliğe ilişkin analizlerde IBM SPSS 20.0 programı kullanılmış olup, DFA' da ise IBM SPSS AMOS programı uygulanmıştır.

\section{Bulgular}

21. Yüzyıl Becerilerinin Öğretimi Ölçeği'nin Türkçeye uyarlama çalışmalarına ilişkin DFA, ölçüt geçerliği ve güvenirlik analizi bulguları aşağıda sırası ile sunulmaktadır.

\section{Doğrulayıcı Faktör Analizi}

Ölçeğin Türkçe formunun, orijinalindeki gibi 10 madde ve üç faktörden oluşan yapıyı doğrulayıp doğrulanmadığını sınamak yani ölçeğin Türkçe formunun yapı geçerliğini test etmek amacıyla DFA uygulanmıştır. DFA ile test edilen modelin yeterliliğini ortaya koymak amacıyla, analizden elde edilen uyum indeksleri uyum ölçütlerine göre değerlendirilmiştir. Bu araştırmada uyum indeksi olarak; örneklem büyüklüğüne göre standardize edilmiş değer 
(X2/sd), GFI (iyilik uyum indeksi), AGFI (düzeltilmiş iyilik uyum indeksi), CFI (karşılaştırmalı uyum indeksi), NNFI (normlaştırılmamış uyum indeksi), IFI (fazlalık uyum indeksi), RMSEA (tahmin hatalarının ortalamasının karekökü) ve SRMR (standartlaştırılmış hata kareleri ortalamasının karekökü) değerleri kullanılmıştır (Hu ve Bentler, 1999). Analiz sonuçlarının yorumlanmasında kullanılan uyum indekslerine ilişkin mükemmel ve kabul edilebilir uyum değer aralıkları ile çalışma kapsamında uygulanan DFA'dan elde edilen değerler Tablo 2'de sunulmaktadır.

Tablo 2.21.yüzyıl becerileri öğretimi ölçeğinin DFA sonuçları

\begin{tabular}{lllll}
\hline $\begin{array}{l}\text { İncelenen Uyum } \\
\text { Indeksleri }\end{array}$ & $\begin{array}{l}\text { Mükemmel } \\
\text { Uyum Ölçütü }\end{array}$ & $\begin{array}{l}\text { Kabul Edilebilir } \\
\text { Uyum Ölçütü }\end{array}$ & $\begin{array}{l}\text { Ölçeğe } \\
\text { İlişkin } \\
\text { Değerler }\end{array}$ & Sonuç \\
\hline $\mathrm{X}^{2} / \mathrm{sd}(\mathrm{CMIN} / \mathrm{DF})$ & $0 \leq \mathrm{X}^{2} / \mathrm{sd} \leq 2$ & $2 \leq \mathrm{X}^{2} / \mathrm{sd} \leq 3$ & 2.241 & Kabul edilebilir uyum \\
\hline GFI & $.95 \leq \mathrm{GFI} \leq 1.00$ & $.90 \leq \mathrm{GFI} \leq 95$ & .945 & Mükemmel uyum \\
\hline AGFI & $.90 \leq \mathrm{AGFI} \leq 1.00$ & $.85 \leq \mathrm{AGFI} \leq .90$ & .906 & Mükemmel uyum \\
\hline CFI & $.95 \leq \mathrm{CFI} \leq 1.00$ & $.90 \leq \mathrm{CFI} \leq .95$ & .929 & Kabul edilebilir uyum \\
\hline NNFI & $.95 \leq \mathrm{TLI} \leq 1.00$ & $.90 \leq \mathrm{TLI} \leq .95$ & .900 & Kabul edilebilir uyum \\
\hline IFI & $.95 \leq \mathrm{IFI} \leq 1.00$ & $.90 \leq \mathrm{IFI} \leq .95$ & .931 & Kabul edilebilir uyum \\
\hline RMSEA & $.00 \leq \mathrm{RMSEA} \leq .05$ & $.05 \leq \mathrm{RMSEA} \leq .08$ & .073 & Kabul edilebilir uyum \\
\hline SRMR & $.00 \leq \mathrm{SRMR} \leq .05$ & $.05 \leq \mathrm{SRMR} \leq .10$ & .00 & Mükemmel uyum \\
\hline
\end{tabular}

Kaynak: (Çokluk, Şekercioğlu ve Büyüköztürk, 2014; Hu ve Bentler, 1999; İlhan ve Çetin, 2014)

Tablo 2' de DFA'dan elde edilen sonuçların GFI, AGFI ve SRMR uyum indeksleri için mükemmel uyum; $X^{2} / \mathrm{sd}(\mathrm{CMIN} / \mathrm{DF}), \mathrm{CFI}$, NNFI, IFI ve RMSEA uyum indekslerinde ise kabul edilebilir uyum düzeyinde olduğu görülmektedir. Bu bulgular ışığında 21.yüzyıl becerileri öğretimi ölçeğinin üç faktörlü yapısının uyum düzeyinin yeterli olduğu söylenebilir. DFA sonucunda elde edilen üç faktörlü model ve maddelerin faktör yükleri ise Şekil 1 'de sunulmaktadır. 


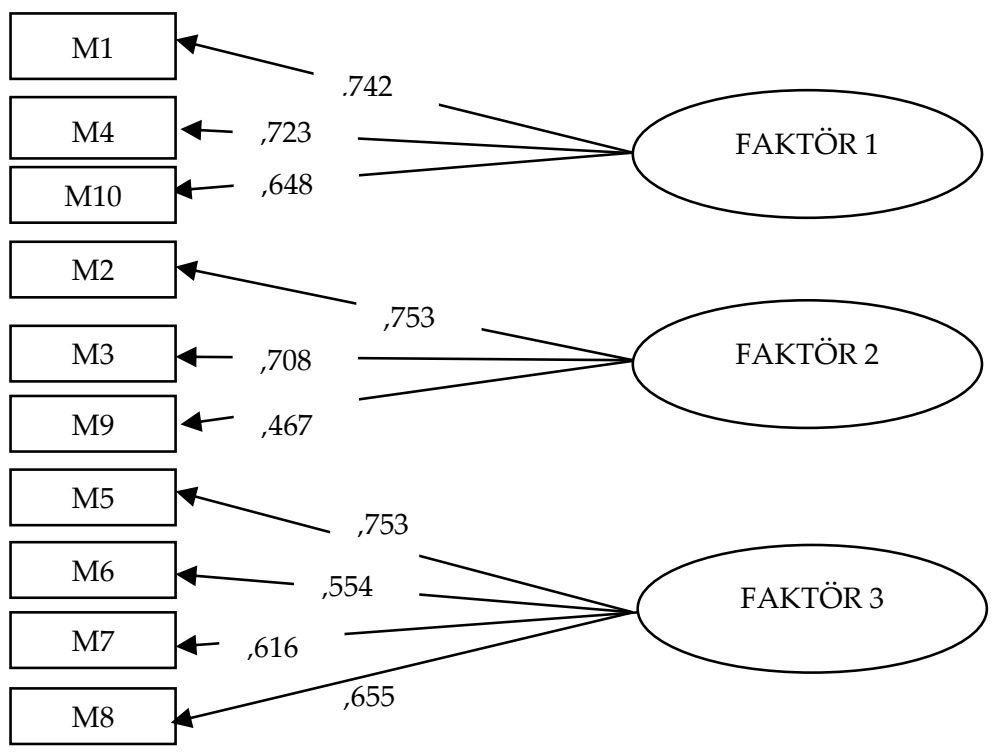

Şekil 1. 21.yüzyıl becerileri öğretimi ölçeğinin standardize edilmiş faktör yükleri

Şekil 1'de görüldüğü üzere, maddelerin faktör yükleri .467 ile .753 arasinda değişmektedir. Bu değerler modelin uygun olduğunun göstergesi olarak kabul edilebilir.

\section{Ölçüt geçerliği}

Ölçeğin ölçüt geçerliğinin, ölçeğin tamamı ile her bir faktör arasındaki korelasyonun incelenmesi ile sağlanması amaçlanmıştır. Bulgular Tablo 3'te verilmektedir.

Tablo 3. Ölçek toplam puanı ve alt boyutlan arasındaki korelasyonlar

\begin{tabular}{lllll}
\hline & & Faktör 1 & Faktör 2 & Faktör 3 \\
\hline \multirow{3}{*}{ Toplam } & Korelasyon katsayıs &, $787^{* *}$ &, $738^{* *}$ &, $848^{* *}$ \\
& $\mathrm{p}$ &, 000 &, 000 &, 000 \\
& $\mathrm{~N}$ & 233 & 233 & 233 \\
\hline \multirow{3}{*}{ Faktör 1 } & Korelasyon katsayıs & &, $375^{* *}$ &, $506^{* *}$ \\
& $\mathrm{p}$ &, 000 &, 000 \\
& $\mathrm{~N}$ & 233 & 233 \\
\hline \multirow{3}{*}{ Faktör 2 } & Korelasyon katsayıs1 & $\mathrm{P}$ & &, $441^{* *}$ \\
& $\mathrm{~N}$ & & &, 000 \\
& & & 233 \\
\hline
\end{tabular}

**Anlamlılıkdüzeyi .01 olarakbelirlenmiştir. 
Tablo 3 incelendiğinde ölçeğin toplam puanı ve her bir faktörden alınan toplam puanlar arasında olumlu yönde, yüksek düzeyde, anlamlı bir ilişki olduğu görülmektedir. Bu bulgu ölçeğin genelinin her bir faktör ile uyumlu bir yapıda olduğunun göstergesi olarak kabul edilebilir. Ayrıca her bir faktörden alınan toplam puanlar arasında olumlu yönde, orta düzeyde, anlamlı bir ilişki olduğu görülmektedir. Faktörler arasındaki ilişkinin orta düzeyde olması ise her bir faktörün kendi içinde uyumlu bir yapıya sahip olduğunun ve faktör yapılarının doğru bir şekilde oluşturulduğunun göstergesi olarak ele alınabilir.

\section{Güvenirlik}

21. yüzyıl becerileri öğretimi ölçeğinin güvenirlik çalışmaları kapsamında ölçeğin tamamının ve her bir faktörünün Cronbach Alfa (iç tutarlık) katsayıları, testi yarılama güvenirliği, madde toplam korelasyonları ve madde ayırt edicilik değerleri yapılan analizlerle incelenmiştir. 10 maddeden oluşan ölçeğin Türkçe formunun tamamında Cronbach Alfa katsayısı .82 olarak hesaplanmıştır. Üç faktörlü yapıya sahip olan ölçeğin alt faktörlerine ilişkin Cronbach Alfa katsayıları ise; birinci faktör için .694, ikinci faktör için .690 ve üçüncü faktör için .736 olarak belirlenmiştir. Testi yarılama güvenirliği analizi sonucunda ise her bir eşdeğer yarıya ilişkin Cronbach Alfa katsayıları sırasıyla .707 ve .712 olarak ölçülmüştür. Güvenirlik analizlerinden elde edilen değerlerin .70'e denk gelmesi veya üzerinde olması, ölçeğin Türkçe formunun güvenilir bir ölçme aracı olduğuna ilişkin önemli kantlardır (Bernardi, 1994). Ölçeğin madde toplam korelasyonu ile \%27'lik alt grup ve \%27'lik üst grup puanları arasındaki farkı belirmek için uygulanan bağımsız gruplar $t$ testi sonucunda elde edilen $t$ değerleri ise Tablo 4 'te sunulmaktadır. 
Tablo 4. 21.Yüzyıl Becerileri Öğretimi Ölçeği'nin madde toplam korelasyonu, madde ayırt edicilik değerleri

\begin{tabular}{|c|c|c|c|c|c|c|}
\hline \multirow[b]{2}{*}{ Faktör } & \multirow[b]{2}{*}{ Madde } & \multirow{2}{*}{$\begin{array}{l}\text { Madde } \\
\text { Toplam } \\
\text { Korelasyonu }\end{array}$} & \multicolumn{2}{|c|}{ Ortalama Puan } & \multirow[b]{2}{*}{$t$} & \multirow[b]{2}{*}{ p } \\
\hline & & & $\begin{array}{l}\% 27^{\prime} \text { lik } \\
\text { alt grup }\end{array}$ & $\begin{array}{l}\% 27^{\prime} \text { lik } \\
\text { alt grup }\end{array}$ & & \\
\hline \multirow{3}{*}{ Faktör 1} & M1 & .633 & 3.88 & 5.80 & -8.107 & .000 \\
\hline & M4 & .630 & 3.45 & 5.77 & -9.859 & .000 \\
\hline & M10 & .627 & 3.96 & 5.85 & -8.857 & .000 \\
\hline \multirow{3}{*}{ Faktör 2} & M2 & .582 & 4.32 & 589 & -7.507 & .000 \\
\hline & M3 & .511 & 4.52 & 5.90 & -7.450 & .000 \\
\hline & M9 & .563 & 4.63 & 5.98 & -6.717 & .000 \\
\hline \multirow{4}{*}{ Faktör 3} & M5 & .576 & 3.87 & 5.74 & -7.703 & .000 \\
\hline & M6 & .549 & 3.29 & 5.31 & -7.396 & .000 \\
\hline & M7 & .530 & 3.56 & 5.47 & -7.461 & .000 \\
\hline & M8 & .600 & 3.80 & 5.87 & -10.268 & .000 \\
\hline
\end{tabular}

$\mathrm{p}<.01$

Tablo 4' te görüldüğü üzere her bir madde için madde toplam korelasyonlar1 .511 ile .633 arasında değişmektedir. Buna göre her bir ölçek maddesi ile ölçeğin genel toplamı arasında olumlu yönde ve orta düzeyde anlamlı bir ilişki vardır ve bu ilişki .00 düzeyinde anlamlıdır. Bu bulgu maddelerin ölçeğin tamamı ile tutarlı olduğunu gösterir niteliktedir. Ölçekten alınan toplam puanlara göre belirlenen $\% 27^{\prime}$ lik alt grup ile $\% 27^{\prime}$ lik üst grup puanları arasındaki farkın anlamlılık durumunu belirlemek için uygulanan bağımsız gruplar $t$ testi sonucunda elde edilen $t$ değerlerinin ise -6.717 ile -10.268 aralığında değiştiği ve yine bu değerlerin de .01 düzeyinde anlamlı olduğu Tablo $4^{\prime}$ te görülmektedir. Bu bulguya göre her bir ölçek maddesinin ayırt edici özelliğe sahip olduğu söylenebilir. Bu bulgu ayrıca araştırmada yer alan katılımcı sayısının faktör analizi için yeterli olduğunun ve modelden çıarılması gereken madde olmadığının da göstergesidir (Byrne, 2010). Tüm bu bulgular ölçeğin Türkçe formunun güvenilir bir ölçme aracı olduğu yönündedir.

\section{Tartışma ve Sonuç}

21. Yüzyıl Becerileri Öğretimi Ölçeğinin Türkçe' ye uyarlanmasının amaçlandığı bu araştırmada geçerlik kapsamında ölçeğin Türkçe formunun dil geçerliğinin sağlanmasına ilişkin çalışmalar yapılmış, yapı (DFA) ve ölçüt geçerliği incelenmiştir. DFA sonucunda standardize edilmiş faktör yüklerinin ikisi hariç tamamının .60 üzeri değer aldığı, GFI, AGFI NFI, X²/sd(CMIN/df), CFI, 
IFI, RMSEA ve SRMR değerlerinin ise mükemmel uyum veya kabul edilebilir uyum indekslerine sahip olduğu belirlenmiştir. DFA'ya ilişkin bu bulgular orijinal ölçeğin yapısına ilişkin sonuçların, Türkçe formu için de doğruland1ğın göstermektedir. Araştırmada, ölçüt geçerliğini sağlamak amacı ile 21. Yüzyıl Becerileri Öğretimi Ölçeğinin alt faktörlerinin ölçeğin tamamı ile korelasyonu incelenmiş; ölçekten alınan toplam puanlar ile her bir faktörden alınan toplam puanlar arasında olumlu yönde, yüksek düzeyde ve anlamlı bir ilişki olduğu belirlenmiştir. Bu sonuç bu üç alt faktörün ölçeğin bileşenlerini doğru olarak temsil ettiğini göstermektedir.

Ölçeğin güvenirlik çalışmaları kapsamında ise ölçeğin tamamının ve üç alt faktörünün iç tutarlık katsayıları, testi yarılama güvenirliği, madde toplam korelasyonları ve madde ayırt edicilik değerleri hesaplanmış, elde edilen değerlerin tamamı ölçeğin güvenilir bir ölçme aracı olduğuna ilişkin kanıt sunmuştur. Ölçeğin tamamının Cronbach Alfa katsayısı .82 olarak belirlenmiş, üç alt faktör ile eşdeğer yarılara ilişkin Cronbach Alfa katsayılarının da güvenirliğe ilişkin yeterli değerlere sahip olduğu tespit edilmiştir (Büyüköztürk, 2007: 171). Araştırmada ayrıca ölçeğin madde toplam korelasyonlarının, maddelerin her birinin ölçeğin tamamı ile tutarlı olduğunu gösterir nitelikte değerlere sahip olduğu (Sönmez ve Alacapınar, 2018: 215) ve \%27'lük alt-üst grup madde ayırt edicilik değerlerine göre de her bir ölçek maddesinin ayırt edici özelliğe sahip olduğu belirlenmiştir. Bu sonuçlara göre; teknolojinin yararı, işbirliği, yenilik ve problem çözme olmak üzere üç alt faktörden ve 10 maddeden oluşan 21. Yüzyıl Becerileri Öğretimi Ölçeği Türkçe Formu'nun (Ek.1), öğretmen adaylarının 21. yüzyıl becerileri öğretimine ilişkin özyeterlik algıların ölçmeye yönelik, güvenilir ve geçerli bir ölçme aracı olduğu söylenebilir.

Bireylere 21. yüzyıl becerilerinin kazandırılmasının gereklilik olduğu dünya genelinde kabul gören bir görüştür (Walser, 2008) ve birçok ülke eğitim sistemlerinde 21. yüzyıl becerilerine yer vermektedir (Adamson ve Darling-Hammond, 2015; Anagün ve diğerleri, 2016; OECD,1010). Bu durum 21. yüzyıl becerilerinin öğrencilere kazandırılmasında öğretmenlere de önemli sorumluluklar yüklemektedir. Sanders ve Rivers' a (1996) göre öğrenme öğretme sürecinde öğretmenin performansı, öğrencinin performansını olumlu yönde etkileyebileceği gibi, olumsuz yönde de etkileyebilmektedir. Yaşad1ğımız yüzyılda bu becerilerin bireylere kazandırılmasının önemi göz önünde bulundurulduğunda, öğretmen performansına dayalı olarak öğrencilere bu 
becerilerin kazandırılamama olasılığının ortadan kaldırılmasına yönelik önlemlerin alınması önem arz etmektedir. Bu konuda alınabilecek en temel önlemlerden biri de öğretmenlerin öğrencilere bu becerileri kazandırabilecek nitelikte yetiştirilmeleridir (P21, 2015; Rotherdam ve Willingham, 2009; Saavedra ve Opfer, 2012). Bunu test etmek de ancak, bu özellikleri ölçebilecek nitelikte geliştirilmiş geçerli güvenilir ölçme araçları ile mümkündür.

Yenilik ve problem çözme, işbirliği ve teknolojiye ilişkin üç alt faktörden oluşan bu ölçek, 21. yüzyıl becerilerine ilişkin birçok sınıflama ve çerçevede ortak olarak önemine vurgu yapılan becerileri kapsar niteliktedir (APEC, 2008; Binkley, Erstad, Herman, Raizen, Ripley ve Rumble, 2010; NETS/ISTE, 2007; OECD, 2005; P21, 2009b). Bu durum ölçeğin öğretmen adaylarının 21. yüzyıl becerilerini öğretimine ilişkin yeterliklerini, bu beceriler arasında en çok öne çıkanlar bağlamında belirlemeye olanak sağladığının göstergesi sayılabilir. Bu bağlamda yapılan araştırma ile geçerliği ve güvenirliği ispatlanmış olan bu ölçme aracının öğretmen yetiştirme alanında, 21. yüzyıl becerileri öğretimi konusunda yapılabilecek çalışmalara da katkı sağlaması beklenmektedir. Bu ölçeğin madde havuzundan faydalanarak Jia ve diğerleri (2010) öğretmenlerin 21. yüzyıl becerilerinin öğretimine ilişkin özyeterlik algılarını ölçmek üzere, farklı bir ölçek çalışması yapmışlardır. Başka bir araştırma ile bu öğretmenlere yönelik ölçeğin Türkçe' ye uyarlama çalışması gerçekleştirilebilir. Bununla birlikte, öğretmenlerin/ öğretmen adaylarının 21. yüzyıl öğretimine ilişkin yeterliklerinin değerlendirilmesinde, alanyazının farklı özelliklerdeki ölçme araçları ile de zenginleştirilmesine yönelik çalışmaların yapılması ayrıca önerilmektedir. 


\title{
EXTENDED ABSTRACT
}

\section{Adaptation of 21st Century Skills Teaching Scale to Turkish Culture: A Validity-Reliability Study}

\author{
Melike Özyurt \\ Gaziantep University
}

Technological developments, scientific innovations, globalization, changing labor demands, economic pressures and rapidly changing competition in today's society have led to redefinition of the skills that individuals need to acquire to contribute to society and be ready for life (Levy and Murnane, 2005; Stewart, 2010 \& Wilmarth, 2010). These skills are defined as $21^{\text {st }}$ century skills and handled in three categories according to Partnership 21 (P21, 2009b). These categories are;

Learning and Innovation Skills, consist of critical thinking and problem solving, creative thinking and innovation, communication, collaboration skills; Life and Career Skills including flexibility and adaptability, entrepreneurship and self-management, social and intercultural skills, productivity and responsibility, leadership and responsibility skills and Information, Media and Technology Skills consist of information literacy, media literacy and information communication technologies literacy (P21, 2009b). In the century we live in, the acquisition of $21^{\text {st }}$ century skills become a fundamental right for individuals (Autor, Levy \& Murnane, 2003; P21, 2008). Because having $21^{\text {st }}$ century skills makes individuals successful both in business life and education life (Ball, Joyce \& Anderson-Butcher, 2016). $21^{\text {st }}$ century skills can be acquisited to individuals through education. In this scope many countries updated their curricula for including $21^{\text {st }}$ century skills; such as critical thinking, problem solving, decision making, communication, cooperation and citizenship (Adamson and Darling-Hammond, 2015; Gelen, 2017; OECD, 2010). Similar approaches also realized in Turkey. In this scope in Turkey, Ministry of National Education was created the "Education Quality Framework" according to "Turkey Qualifications Framework" which is in line with the "European Qualifications Framework". The eight key competences, related with 
$21^{\text {st }}$ century skills, were determined in "Turkey Qualifications Framework" were included in all curricula.

In order to implement curricula enriched with $21^{\text {st }}$ century skills, first of all teachers should be competent in teaching these skills. However, when the literature was examined, it could not be reached a Turkish measurement tool that could measure teachers' or prospective teachers competencies in $21^{\text {st }}$ skills teaching. In this context to fill the gap in the literature and contribute to teacher training curricula in the scope of evaluating prospective teachers' proficiencies in teaching $21^{\text {st }}$ century skills; the purpose of the study was determined as, to adapt the $21^{\text {st }}$ Century Skills Teaching Scale into Turkish and investigate the psychometric properties of the scale.

The research was conducted with 233 prospective teachers, studying in Gaziantep University Education Faculty, in the Fall Term of 2019-2020 Academic Year. The " $21^{\text {st }}$ Century Skills Teaching Scale" developed by Jia, Oh, Sibuma, LaBanca ve Lorentson (2016), serves the purpose of measuring prospective teachers' self-efficacy perceptions regarding the teaching of $21^{\text {st }}$ century skills This 7 likert type scale consists of 10 items and three factors. Subfactors of the scale are utility of technology (three items), collaboration (three items) and innovation - problem solving (four items). In the adaptation process of the scale to Turkish, linguistic validity, conceptual and experiential equivalence, construct validity, criterion validity and reliability studies were carried out. In order to ensure the linguistic validity of the Turkish form of the scale, translation back translation technique was applied and expert opinions were asked. For testing conceptual and experiential equivalence of the scale, the Turkish and English forms of the scale were implemented to a group of prospective teachers from Foreign Languages department in 8 weeks period and correlation between the results were calculated. Confirmatory Factor Analysis (CFA) was applied to test the construct validity. To test the criterion validity, the correlation between the whole scale and each subfactor was examined. Within the scope of reliability studies, Cronbach Alfa (internal consistency) reliability coefficients of the scale, half-test reliability, item total correlations and item discrimination values were calculated.

CFA was applied to test the construct validity of the Turkish form of the scale. The results from CFA indicated that there were perfect fit level for GFI 0.945, AGFI 0.906 and SRMR .00 indices, and acceptable fit level in X2 / sd 2.241, CFI .929, NNFI .900, IFI .931 and RMSEA .073 indices. Factor loads of 
items vary between .467 and .753 . According to this findings it can be said that the level of adaptation of the three-factor structure of the $21^{\text {st }}$ century skills teaching scale was sufficient(Cokluk, Sekercioglu \& Buyukozturk, 2014; Hu \& Bentler, 1999; Ilhan \& Cetin, 2014). It is also found that there was a positive, high level and meaningful relationship between the total score of the scale and the total scores from each factor. It was also determined that there was a positive, medium-level and significant relationship between the total scores of each factor. The Cronbach Alpha coefficient of the scale was calculated as .82. Cronbach Alpha coefficients regarding the sub-factors of the scale were calculated as.694 for the first factor,.690 for the second factor and .736 for the third factor. According to the test half-reliability analysis results, the Cronbach Alpha coefficients for each equivalent half were measured as .707 and .712 , respectively. The results of the independent samples t-test which was implemented to the $27 \%$ top group and $27 \%$ bottom group was between -6.717 and -10.268 and significant.

As a result of the research, it has been determined that the $21^{\text {st }}$ Century Skills Teaching Scale Turkish Form is a valid and reliable measurement tool that can be used to measure the self-efficacy perceptions of prospective teachers regarding $21^{\text {st }}$ century skills teaching. All of these results provided evidence that the scale is a valid and reliable measurement tool. In addition to these; the scale includes the items referring to skills emphasized in many classifications and frameworks related to $21^{\text {st }}$ century skills (APEC, 2008; Binkley, Erstad, Herman, Raizen, Ripley ve Rumble, 2010; NETS/ISTE, 2007; OECD, 2005; P21, 2009b). This can be also considered as the scale allows determining the competencies of prospective teachers' in teaching $21^{\text {st }}$ century skills via their self efficiency perceptions. As a result the Turkish form of the scale is expected to contribute to the studies on $21^{\text {st }}$ century skills teaching in the field of teacher training. Considering the importance of teacher competence in teaching $21^{\text {st }}$ century skills, it is also recommended to carry out studies for enriching the literature with different measurement tools in the evaluation of the competencies of teachers for $21^{\text {st }}$ century teaching. 


\section{Kaynakça / References}

Adamson, F. ve Darling-Hammond, L. (2015). Policy pathways for twenty-first century skills. Assessment and teaching of 21st century skills içinde (s.293-310). Springer, Dordrecht.

Anagün, Ş. S., Atalay, N., Kılıç, Z. ve Yaşar, S. (2016). Öğretmen adaylarına yönelik 21. yüzyıl becerileri yeterlilik algıları ölçeğinin geliştirilmesi: Geçerlik ve güvenirlik çalışması. Pamukkale Üniversitesi Eğitim Fakültesi Dergisi, 40(40), 160-175.

Arsad, N. M., Osman, K.ve Soh, T. M. T. (2011). Instrument development for $21^{\text {st cen- }}$ tury skills in Biology. Procedia-Social and Behavioral Sciences, 15, 1470-1474.

Autor, D.H., Levy, F., ve Murnane, R.J. (2003). The skill content of recent technological change: An empirical exploration. Quarterly Journal of Economics, 118(4), 12791333.

Ball, A., Joyce, H. D. ve Anderson-Butcher, D. (2016). Exploring 21 ${ }^{\text {st }}$ century skills and learning environments for middle school youth. International Journal of School Social Work, 1(1), 1-15.

Belet-Boyac, S. D. ve Atalay, N. (2016). A scale development for $21^{\text {st }}$ century skills of primary school students: A validity and reliability study. International Journal of Instruction, 9(1), 133-148.

Bernardi, R. A. (1994). Validating research results when Cronbach's alpha is below .70: A methodological procedure. Educational and Psychological Measurement, 54(3), 766-775.

Binkley, M., Erstad, O., Herman, J., Raizen, S., Ripley, M. ve Rumble, M. (2010). Draft white paper 1: Defining 21 $21^{\text {st }}$ century skills. 20.04.2020 tarihinde https://oei.org.ar/ibertic/evaluacion/sites/defult/files/biblioteca/24defining21st-century-skills.pdf adresinden erişilmiştir.

Bryman, A. ve Cramer, D. (2001). Quantitative data analysis with SPSS release 10 for Windows. New York.

Büyüköztürk, Ş. (2007). Sosyal bilimler için veri analizi el kitabı. Ankara: PegemA Yayınclik.

Byrne, B. M. (2010). Structural equation modeling with AMOS: Basic concepts, applications and programming (2nd Edition). New York: Routledge.

Cansoy, R. (2018). Uluslararası çerçevelere göre 21.yüzyıl becerileri ve eğitim sisteminde kazandırılması. İnsan ve Toplum Bilimleri Araştırmaları Dergisi, 7(4), 3112-3134.

Comrey, A. L., ve Lee, H. B. (1992). A first course in factor analysis (2nd Edition). Hillsdale, NJ: Erlbaum. 
Çevik, M. veŞentürk C. (2019). Multidimensional 21 ${ }^{\text {st }}$ century skills scale: Validity and reliability study. Cypriot Journal of Educational Sciences.14(1), 11-028.

Çokluk, Ö., Şekercioğlu, G., ve Büyüköztürk, Ş. (2010). Sosyal bilimler için çok değişkenli istatistik: SPSS ve LISREL uygulamaları (3. Baskı). Ankara: Pegem Akademi.

Deborah, L. E., (2012). A new generation: A new model of education in the 21 st century. Unpublished Dissertation. University of Southern California.

Dede, C. (2010). Comparing frameworks for 21st century skills. J. Bellanca ve R. Brandt (Ed.), 21 ${ }^{\text {st }}$ century skills: Rethinking how students learn içinde(s.51-76). Bloomington, IN: Solution Tree Press.

European Comission. (2006). Key competences for lifelong learning, European Communities, Belgium. 17.04.2020 tarihinde https://eur-lex.europa.eu/legal-content/ EN/TXT/PDF/?uri=CELEX:52018SC0014\&from=EN.

European Comission (2018). Developing key competencies all for throughout life. 17.04.2020tarihindehttps://ec.europa.eu/education/sites/education/files/document-librarydocs/factsheetkey-competences-lifelong-learning_en.pdf adresinden erişilmiştir.

Floyd, F. J. ve Widaman, K. F. (1995). Factor analysis in the development and refinement of clinical assessment instruments. Psychological Assessment, 7(3), 286299. doi:10.1037/1040-3590.7.3.286.

Gore, V. (2013). 21 st century skills and prospective job challenges. The IUP Journal of Soft Skills, 7(4), 7-14.

Griffin, P., McGaw, B. ve Care, E. (Ed.). (2012). Assessment and teaching of $21^{\text {stcentury }}$ skills. Dordrecht, Netherlands: Springer.

Griffin, P., ve Care, E. (Ed.). (2014). Assessment and teaching of 21st century skills:Methods and approach. Springer.

Gürültü, E., Aslan, M. ve Alcı, B. (2019). Ortaöğretim öğretmenlerinin 21. Yüzyıl becerileri kullanım yeterlikleri. Hacettepe Üniversitesi Ĕ̆itim Fakültesi Dergisi. Advance online publication. doi: 10.16986/HUJE.2019051590.

Hu, L. ve Bentler, P. M. (1999). Cutoff criteria for fit indexes in covariance structure analysis: conventional criteria versus new alternatives. Structural Equation Modeling, 6(1), 1-55.

İlhan, M. ve Çetin, B. (2014). Sınıf değerlendirme atmosferi ölçeğinin (SDAÖ) geliştirilmesi:Geçerlik güvenirlik çalışması. Ĕ̆itim ve Bilim, 39(176), 51-68.

Jia, Y., Oh, Y. J., Sibuma, B., LaBanca, F., veLorentson, M. (2016). Measuring twentyfirst century skills: Development and validation of a scale for in service and pre-service teachers. Teacher Development, 20(2), 229-252. 
Kang, M., Heo, H., Jo, I., Shin, J. ve Seo, J. (2010). Developing an educational performance indicator for new millennium students. Journal of Research on Technology in Education, 43(2), 157-170.

Kang, M., Kim, M., Kim, B. ve You, H. (2012). Developing an instrumen to measure $21^{\text {st }}$ century skills for elementary student. The Korean Journal of Eductional Methodolocy Studies, 25(2).

Karakaş, M. M. (2015). Ortaokul sekizinci sinı öğrencilerinin fen bilimlerine yönelik 21. yüzyıl beceri düzeylerinin ölçülmesi. Yayınlanmamış Yükseklisans Tezi. Osmangazi Üniversitesi, Eğitim Bilimleri Enstitüsü, Eskişehir, Türkiye.

Kellner, D. (2000). New technologies/new literacies: Reconstructing education for the new millennium. Teaching Education 11(3), 245-265.

Keskin, İ. ve Yazar, T. (2015). Öğretmenlerin yirmi birinci yüzyıl becerileri ışığında ve yaşam boyu öğrenme bağlamında dijital yeterliliklerinin incelenmesi. Uluslar arast Insan Bilimleri Dergisi, 12(2), 1691-1711. doi:10.14687/ijhs.v12i2.3503.

Kline, R. B. (2011). Principles and practice of structural equation modeling. New York: Guilford publications.

Levy, F. ve Murnane, R. (2005). How computerized work and globalization shape human skill demand, IPC Working Paper series MIT-IPC-05006. Massachusetts Institute of Technology.

Looman, W.S. ve Farrag, S. (2009). "Psychometric properties and cross-cultural equivalence of the Arabic Social Capital Scale: Instrument development study". International Journal of Nursing Studies. 46, 45-54.

Louis, R.C. (2012). A case study exploring technology use and incorporation of $21^{\text {st }}$ century skills in elementary classrooms. Unpublished dissertation. University of Boston.

Orhan-Göksun, D. (2016). Öğretmen adaylarmm 21. yy. öğrenen becerileri ve 21. yy. öğreten becerileri arasındaki ilişki. Yayımlanmamış doktora tezi. Anadolu Üniversitesi, Eğitim Bilimleri Enstitüsü, Eskişehir.

Ongardwanich, N., Kanjanawasee, S.veTuipae, C. (2015). Development of 21stcentury skill scales as perceived by students. Procedia-Social and Behavioral Sciences, 191(52), 737-741.

Ontario Ministry of Education. (2010). Building a national education system for the 21 $1^{\text {st }}$ century: Case Study Finland. 20.12.2019 tarihinde http://www.edu.gov.on.ca/bb4e/materials.html adresinden erişilmiştir.

Organization for Economic Cooperation and Development (OECD). (2005). The definition and selection of key competencies: Executive summary. Paris. France. 
Organization of Economic Cooperation and Development(OECD). (2010). Strong performers and successful reformers in education: Lessons from PISA for the United States. 20.12.2019 tarihinde http://dx.doi.org/10.1787/9789264096660-en adresinden erişilmiştir.

Osman, K., Soh, T. M. T., ve Arsad, N. M. (2010). Development and validation ofthe Malaysian 21st century skills instrument (M-21CSI) for science students. Procedia Social and Behavioral Sciences, 9, 599-603.

Partnership for 21st Century Skills (P21). (2008). 21 ${ }^{\text {st }}$ century skills, education Ecompetitiveness: A resource and policy guide. Tucson. AZ: Author. https://files.eric.ed.gov/fulltext/ED519337.pdf adresinden erişilmiştir.

Partnership for 21st Century Skills (P21). (2009a). Framework for 21st century learning. Tucson. AZ: Author. 04.07.2019 tarihinde https://www.teacherrambo.com/ file.php/1/21stcentury skills.pdf. adresinden erişilmiştir.

Partnership for 21st Century Skills (P21). (2019). Framework for 21st century learning. Battlee for Kids. 04.07.2019 tarihinde http://static.battelleforkids.org/ documents/p21/P21_FrameworkBrief.pdf. adresinden erişilmiştir.

Rotherham, A. J. ve Willingham, D. (2009). To work, the 21st century skills movement will require keen attention to curriculum, teacher quality, and assessment. Educational leadership, 9(1), 15-20.

Saavedra, A. R. ve Opfer, V. D. (2012). Teaching and learning $21^{\text {st }}$ century skills: Lessons from the learning sciences. A Global Cities Education Network Report. New York, Asia Society.

Saavedra, A. R. ve Opfer, V.D. (2012). Learning 21st-century skills requires $21^{\text {stcentury }}$ teaching. Phi Delta Kappan, 94(2), 8-13.

Singapore Ministry of Education.(2010). Press Release: MOE to enhance learning of

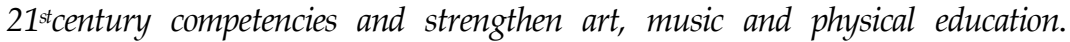
20.04.2020 tarihinde http://www.moe.gov.sg/media/press/2010/03/moe-toenhance-learning-of-21s.php adresinden erişilmiştir.

Sönmez, V. ve Alacapınar, F. G. (2018). Örneklendirilmiş bilimsel araştırma yöntemleri. (6. Baskı). Ankara: Anı Yayıncilık.

Sperber, A. D.(2004). Translation and Validation of Study Instruments for CrossCultural Research". Gastroenterology. 126, 124-128.

Stewart, V. (2010). A classroom as wide as the world. Curriculum 21: Essential Education for a Changing World. H. Hayes Jacobs (Ed.). 97-114. Alexandria. VA : Association for Supervision and Curriculum Development.

Tondeur, J., Aesaert, K., Pynoo, B., van Braak, J., Fraeyman, N. ve Erstad, O.(2017). Developing a validated instrument to measure preservice teachers' ICT 


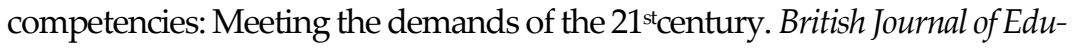
cational Technology, 48(2), 462-472.

TTKB (2017). Müfredatta yenileme ve değişiklik çalışmalarımı üzerine...16.04.2020 tarihinde https:/tttkb.meb.gov.tr/meb_iys_dosyalar/2017_07/18160003bas inaciklamasi program.pdf adresinden erişilmiştir.

Türk Sanayicileri ve İşadamları Derneği, (TÜSİAD). (2012). Basın bültenleri. 20.04.2020 tarihinde http://www.tusiad.org.tr/bilgi-merkezi/basin-odasi /basin-bultenleri/ adresinden erişilmiştir.

Voogt, J. ve Roblin, N. P. (2010). 21 ${ }^{\text {st }}$ century skills. Discussienota. Zoetermeer: The Netherlands: Kennisnet, 23(03), 2000.

Voogt, J. ve Roblin, N. P. (2012). A comparative analysis of international frameworks for $21^{\text {st }}$ century competences: Implications for national curriculum policies. Journal of Curriculum Studies, 44(3), 299-321. doi:10.1080/00220272.2012. 668938.

Yılmaz, E., ve Alkış, M. (2019). 21. yüzyıl yeterlilikleri ölç̧ğinin geliştirilmesi: Geçerlik ve güvenirlik çalışması. The Journal of International Lingual Social and Educational Sciences, 5(1), 125-154.

Walser, N. (2008). Teaching 21st century skills. Harvard Education Letter, 24(5),1-3.

Wilmarth, S. (2010). Five socio-technology trends that change everything in learning and teaching. H. H. Jacobs (Ed.). Curriculum 21: Essential education for a changing world. Içinde (s.80-96). Alexandria. VA: Association for Supervision and Curriculum Development. 


\section{Ekler}

Ek.1 21. Yüzyıl Becerileri Öğretimi Ölçeği Türkçe Formu

\begin{tabular}{|c|c|c|c|c|c|c|c|c|}
\hline & & 离 & (6) & (5) & (4) & (3) & (2) & 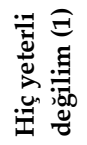 \\
\hline 1. & $\begin{array}{l}\text { Öğrencilere konuları anlamaları için bilgiye eri- } \\
\text { şimde dijital araçların kullanımını öğretmekte } \\
\text { (dijital araçlar: çevrim içi kitaplar ve makaleler, } \\
\text { İnternet araştırmaları, çevrim içi tartışmalar, in- } \\
\text { ternet sitelerinden veya çevrim içi veri tabanla- } \\
\text { rından bilgi toplamak), }\end{array}$ & & & & & & & \\
\hline 2. & $\begin{array}{l}\text { Öğrencilere bir grup projesinde liderlik etmeyi } \\
\text { öğretmekte, }\end{array}$ & & & & & & & \\
\hline 3. & $\begin{array}{l}\text { Bir projedeki amacı gerçekleştirmek için öğren- } \\
\text { cileri akranlarıyla işbirliğine yönlendirmekte, }\end{array}$ & & & & & & & \\
\hline 4. & $\begin{array}{l}\text { Öğrencilere, bilgiyi açık bir şekilde iletmek için } \\
\text { teknolojik araçları (ör. Çevrim içi forumlar/tar- } \\
\text { tışma, Powerpoint sunular, dijital medya pro- } \\
\text { jesi) kullanmayı öğretmekte, }\end{array}$ & & & & & & & \\
\hline 5. & $\begin{array}{l}\text { Öğrencileri “gerçek yaşam” zorluklarını veya } \\
\text { problemlerini tanımaya yönlendirmekte, }\end{array}$ & & & & & & & \\
\hline 6. & $\begin{array}{l}\text { Öğrencilere bir zorluk (ör. Dijital animasyon, } \\
\text { petrol sızıntısının temizlenmesi, nanoteknoloji- } \\
\text { nin uygulanması) için yenilikçi bir çözüm belir- } \\
\text { lemeyi öğretmekte, }\end{array}$ & & & & & & & \\
\hline 7. & $\begin{array}{l}\text { Öğrencilere bir ürüne ilişkin geliştirdikleri bir } \\
\text { fikrin kalitesini değerlendirmeyi öğretmekte, }\end{array}$ & & & & & & & \\
\hline 8. & $\begin{array}{l}\text { Öğrencilere bir projeden elde edilen verilerin } \\
\text { veya kanıtın geçerliliğini değerlendirmeyi öğret- } \\
\text { mekte, }\end{array}$ & & & & & & & \\
\hline 9. & $\begin{array}{l}\text { Öğrencilere farklı kültürlerden bireylerle saygı } \\
\text { çerçevesinde çalışmayı öğretmekte, }\end{array}$ & & & & & & & \\
\hline 10. & $\begin{array}{l}\text { Öğrencilere teknolojiyi sorumlu bir şekilde (ör. } \\
\text { Dijital kimliği korumak, başkalarını haklarını } \\
\text { korumak, lisanslama kanunlarına uymak) kul- } \\
\text { lanmayı öğretmekte, }\end{array}$ & & & & & & & \\
\hline
\end{tabular}

Faktör 1: Teknolojinin Yararı (1, 4 ve 10. maddeler)

Faktör 2: İşbirliği (2, 3 ve 9. maddeler)

Faktör 3: Yenilik ve Problem Çözme (5, 6, 7 ve 8. maddeler) 


\section{Kaynakça Bilgisi / Citation Information}

Özyurt, M. (2020).21. yüzyıl becerileri öğretimi ölçeğinin Türk kültürüne uyarlanması: Geçerlik güvenirlik çalışması. OPUS-Uluslararası Toplum Araştırmaları Dergisi, 16(30), 2568-2594. DOI: 10.26466/opus.725042 